\title{
SAFETY AND EFFICACY OF LOW MOLECULAR WEIGHT HEPARIN (ENOXAPARIN SODIUM) IN COMPARISON WITH STANDARD UNFRACTIONATED HEPARIN FOR HAEMODIALYSIS ANTICOAGULATION
}

\author{
Emad Abdallah, MD; Samya El-Shishtawy, MD; Osama Mosbah, MD
}

Nephrology Department, Theodor Bilharz Research Institute, Cairo, Egypt

\begin{abstract}
\section{BACKGROUND}

Low molecular weight heparin (LMWH) has been suggested as safe, efficient and convenient anticoagulation for haemodialysis (HD) than unfractionated heparin (UFH), with fewer side effects. The objective of this study was to compare LMWH with UFH during haemodialysis in patients with end-stage renal disease (ESRD) to obtain precise estimates of clinically important outcomes, including bleeding rates and thrombosis of the extracorporeal circuit.
\end{abstract}

\section{METHOD}

In this prospective, randomised, cross-over study we compared the safety, clinical efficacy and cost effectiveness of enoxaparin sodium with unfractionated heparin in 44 patients (31 males, 13 females; mean age $53.7 .9 \pm 14.2$ years) with end-stage kidney disease (ESKD) on regular haemodialysis. They were randomly assigned to either enoxaparin sodium $(40 \mathrm{mg})$ or standard heparin, and followed prospectively for 16 weeks (48 dialyses sessions) before crossing over to the alternate therapy for a further 16 weeks. Heparin anticoagulation was monitored using activated coagulation times. Clinical clotting and haemorrhaging were evaluated by visual inspection after blood draining of the air trap, blood lines and dialysers. To determine whether the type of anticoagulation had any effect on the adequacy of dialysis using Kt/V and lipid profile were measured.

\section{RESULTS}

The present study showed that, compared with UFH, the effect of LMWH enoxaparin sodium on the number of haemorrhagic events (relative risk, 1.3; 95\% CI: $0.317-5.613 ; \mathrm{p}=1.000$ ), bleedings evaluated by vascular access compression time (weighted mean difference, $-0.65 ; 95 \% \mathrm{CI}$ : -1.55 - 0.82), or extracorporeal circuit thrombosis (relative risk, $0.75 ; 95 \% \mathrm{CI}: 0.284-1.984 ; \mathrm{p}=1.000$ ) was not significant. There was no significant difference in $\mathrm{Kt} / \mathrm{V}$ between the groups $(1.5 \pm 1.2$ for enoxaparin sodium vs $1.4 \pm 0.4$ for heparin; $\mathrm{p}=0.6)$. There was no significant differences in serum total cholesterol, LDL, HDL and TGs after using either anticoagulant.

\section{CONCLUSION}

Enoxaparin sodium should be considered as effective and safe as unfractionated heparin and is more convenient than UFH in haemodialysis patients. But, currently direct costs are about $28 \%$ more.

\section{KEY WORDS}

Aticoagulation, hemodialysis, heparin, enoxaparin.

CORRESPONDING AUTROR: Emad Abdallah, MD, associate professor of nephrology, Nephrology Department, Theodor Bilharz Research Institute, Cairo, Egypt. E-mail: abdallahemad66@yahoo.com 


\section{INTRODUCTION}

Low molecularweight heparins (LMWH) are increasingly used for the prevention and treatment of many thromboembolic disorders because they are as effective and more convenient than unfractionated heparin (UFH) (1). The predictable anticoagulant effect of LMWH eliminates the need for routine laboratory monitoring, allowing many patients with thrombosis to be treated without hospital admission. Other advantages include lower incidences of heparin-induced thrombocytopenia and osteoporosis compared with UFH.

Some important differences exist between LMWH and UFH. Unlike UFH, which inhibits factor Xa and thrombin equally, LMWH have greater activity against factor Xa. The anticoagulant effects of LMWH therefore are monitored by measuring the ability of plasma from patients who are treated with LMWH to inhibit factor Xa; the resultant assay is known as an anti-Xa heparin level. This level reflects the amount of LMWH present in the blood and, by extension, the degree of anticoagulation. Although the minimal therapeutic antiXa level has not been established, a conservative therapeutic range measured $4 \mathrm{~h}$ after a subcutaneous dose is $0.6-1.0 \mathrm{IU} /$ $\mathrm{ml}$ for twice-daily administration and $1.0-2.0 \mathrm{IU} / \mathrm{ml}$ for once-daily dosing ( $\underline{2})$.

Another important difference is that UFH is cleared through hepatic and renal mechanisms, whereas LMWH are dependent on renal clearance. Thus, patients with renal failure are potentially at risk for bleeding as a result of impaired LMWH clearance and prolonged anticoagulant effects. Observational studies and randomised trial data report increased bleeding using LMWH in patients with renal insufficiency compared with those without renal impairment $(\underline{3}, 4,5,6)$. Moreover, LMWH are more expensive in comparison to UFH (7).

LMWH have high bioavailability, and supposedly less complications as they do not bind to plasma proteins, platelets, and endothelium as much as heparin does (8). It appears that LMWH do not stimulate plasma lipase activity to the same extent as $\mathrm{UFH}(9)$.

Despite the fact that LMWH are infrequently used for therapeutic anticoagulation in patients who require haemodialysis, they are used to prevent thrombosis of the extracorporeal dialysis circuit. LMWH are not removed from the plasma during haemodialysis (10) or continuous veno-venous haemofiltration (11). Thus, LMWH pose a risk of bioaccumulation and bleeding when used repeatedly for haemodialysis. Randomised controlled trials have evaluated LMWH for preventing thrombosis of the dialysis circuit and are approved for this indication in many countries.

The objective of this study was to compare LMWH with UFH during haemodialysis in patients with ESRD to obtain precise estimates of clinically important outcomes, including bleeding rates and thrombosis of the extracorporeal circuit.

\section{PATIENTS AND METHODS}

Our prospective, randomised, cross-over study included 44 adult patients (31 males, 13 females; mean age 53.7.9 \pm 14.2 years) with ESKD on regular haemodialysis in the Theodor Bilharz Research Institute (TBRI), Cairo, Egypt. Informed consent was obtained from all participants.

Patients received haemodialysis three times a week for $4 \mathrm{~h}$ per session at blood flow rates of $250-300 \mathrm{ml} / \mathrm{min}$, mainly with polysulfone membrane dialysers. Vascular access was via arteriovenous fistula.

Exclusion criteria:

1. Patients with known bleeding disorders.

2. Patients receiving oral or other forms of anticoagulant therapy (eg, warfarin, aspirin).

Patients continued their usual medication (including lipidlowering therapy). Human recombinant erythropoietin was given where necessary to maintain target haemoglobin of $11-12 \mathrm{~g} / \mathrm{dl}$.

Patients were randomly assigned to continue receiving standard sodium heparin and followed prospectively for 16 weeks (48 dialyses). The same patients were then crossed over to enoxaparin sodium (Clexane; $40 \mathrm{mg}$ ) and followed for a further 16 weeks (48 dialyses).

Heparin (sodium heparin $5000 \mathrm{IU} / \mathrm{ml}$ ) was administered as a bolus dose (50 IU $/ \mathrm{kg}$ body weight) intravenously into the pre-dialyser arterial line of the extracorporeal blood circuit, followed by a maintenance dose of $1000 \mathrm{IU}$ sodium heparin per hour. Infusion was discontinued $1 \mathrm{~h}$ prior to cessation of HD. LMWH, enoxaparin sodium (Clexane; 40mg) was administered three to four minutes before dialysis as a bolus dose, into the arterial line pre-dialyser. Monitoring of anticoagulation was carried out by visual inspection of the arterial bubble trap every 30 to 60 minutes, as well as the blood lines and the dialyser after the session.

For evaluating the efficacy of anticoagulation, the frequency and degree of clot and fibrin formation in both the dialyser and lines were scored on a four-point scale, with one indicating no clot formation and four indicating severe clotting or total occlusion. This assessment was done after the blood had been returned to the patient by flushing the dialyser and lines with normal saline. Haemorrhage or thrombosis, during and between dialyses, was also noted. Clinical clotting and haemorrhage were evaluated by visual inspection.

Haemorrhages were categorised as weak, moderate, and severe. The dialysis adequacy - evidenced by Kt/V.

Fasting standard lipid profiles were determined at the end of each arm of the study. Total cholesterol (TC), low density lipoprotein (LDL), high density lipoprotein (HDL), and triglycerides (TG) were measured. 


\section{STATISTICAL ANALYSIS}

Quantitative data are expressed as Mean \pm Standard Deviation or percentage. There was no difference between the two sections of the study, therefore data for each phase was pooled. The distribution of variables was evaluated by the One-Sample Kolmogorov-Smirnov Test, and the differences between variables were determined using paired t-test for parametric data or Wilcoxon Signed Ranks Test for non-parametric data as appropriate. The analysis was performed using Statistical Analysis System, version 6.03, on an IBM personal computer and MedCalc for Windows (version 12.7.5). P value $<0.05$ was considered significant.

\section{RESULTS}

The most causes of ESRD were glomerulonephritis, diabetes mellitus and hypertension. Demographic characteristics of the studied patients are shown in Table 1.

With UFH, clotting was noted in eight of the 44 patients $(18.2 \%)$ [Figure 1] and bleeding occurred in three of the 44 patients $(6.1 \%)$ [Figure 2]. With enoxaparin sodium (40mg), clotting was noted in six of the 44 patients $(13.6 \%)$ [Figure 1] and bleeding occurred in four of the 44 patients $(9.1 \%)$ [Figure 2].

Compared with UFH, the effect of LMWH on the number of haemorrhagic events (relative risk, 1.3; 95\% CI: 0.317 - 5.613; $\mathrm{p}=1.000$ ), bleedings evaluated by vascular access compression time (weighted mean difference, $-0.65 ; 95 \%$ CI: -1.55 - 0.82), or extracorporeal circuit thrombosis (relative risk, 0.75 ; 95\% CI: $0.284-1.984 ; \mathrm{p}=1.000$ ) was not significant.

None of the episodes of clotting were severe enough to warrant change of the dialyser or blood lines. None of the bleeding episodes on enoxaparin required blood transfusions, and the bleeding could be controlled by venous compressions at the site of the arteriovenous fistula.

To determine whether the type of anticoagulation had any effect on the adequacy of dialysis using $\mathrm{Kt} / \mathrm{V}$. There was no significant difference between the groups $(1.5 \pm 1.2$ for Clexane vs $1.4 \pm 0.4$ for heparin; $\mathrm{p}=0.6$ ) [Table 2].

There was no significant differences in serum total, cholesterol, LDL, HDL and TGs after using either anticoagulant (Table 2).

By calculating the cost of both anticoagulants, currently direct costs of LMWH are about $28 \%$ more than UFH.

\section{DISCUSSION}

The present study showed that, compared with UFH, the effect of LMWH on the number of haemorrhagic events (relative risk, 1.3; 95\% CI: $0.317-5.613$; $\mathrm{p}=1.000$ ), bleedings evaluated by vascular access compression time (weighted mean difference, -0.65; 95\% CI: -1.55 - 0.82), or extracorporeal circuit thrombosis (relative risk, $0.75 ; 95 \%$ CI: $0.284-1.984 ; \mathrm{p}=1.000$ ) was not significant.

Our results are consistent with a Meta-Analysis carried out by Lim et al where it was shown that the number of haemorrhagic events, bleedings assessed by vascular access compression time, or extracorporeal circuit thrombosis, are not significantly affected by LMWH (relative risk, 1.15; $95 \%$ CI, 0.70 to 1.91 ) in comparison to UFH. Compared with UFH, LMWH appears to be as safe (in terms of bleeding complications) and as effective (in preventing extracorporeal circuit thrombosis). However, until larger, more exact randomised trials are conducted, no strong conclusion can be made from these trials assessing anticoagulation for patients who undergo haemodialysis $(\underline{12})$.

Aggarwal et al showed that in contrast to UFH, the use of enoxaparin sodium as an anticoagulant during haemodialysis, is associated with less platelet reactivity. Therefore, patients with ESRD treated with haemodialysis may benefit from enoxaparin sodium administration, as it decreases the risk of cardiac events (13).

Lim et al in another Meta-Analysis of 11 randomised trials demonstrated that in patients with severe renal insufficiency (creatinine clearance $\leq 30 \mathrm{~mL} / \mathrm{min}$ ) compared with those without (creatinine clearance $>30 \mathrm{~mL} / \mathrm{min}$ ), the use of a standard therapeutic-dose LMWH (enoxaparin sodium) leads to higher levels of anti-Xa. Consequently there is a two- to threefold increase in the risk of major bleeding events (14).

Lim found that, compared with UFH, the effect of LMWH on the number of haemorrhagic events (relative risk, 0.96; 95\% CI: 0.27 - 3.43), bleedings evaluated by vascular access compression time (weighted mean difference, $-0.87 ; 95 \%$ CI: -2.75 - 1.02), or extracorporeal circuit thrombosis (relative risk, 1.15 ; 95\% CI: 0.70 - 1.91) was not significant. In comparison to UFH, LMWH has the same amount of efficacy in preventing extracorporeal circuit thrombosis and is as safe in terms of bleeding complications. However, drawing strong conclusions from these trials assessing anticoagulation for patients who undergo haemodialysis requires more rigorous randomised trials $(\underline{14})$.

In a study Guillet suggests that in haemodialysis patients there is an increased risk of bleeding up to 10 hours after the injection of LMWH enoxaparin sodium (15).

As reported by Saltissi, early in the use of the enoxaparin sodium, minor interdialytic haemorrhaging (none requiring clinical intervention) increased among patients, which might be unnoticed until after four to eight dialyses. There was no difference in the frequency of bleeding or thrombosis between the groups (16).

In a review article, Schmid proposed a detailed approach for LMWH administration in patients with severe renal insufficiency. In brief, this approach included: evaluation 
of the patient's renal function, imminent interventions, and general bleeding risk before prescribing LMWH. LMWH has higher efficacy and lower bleeding risks in general. In unstable patients, or patients who have a high tendency for haemorrhaging, IV UFH is preferred to SC LMWH, as IV UFH has a shorter half-life time, and can be quickly antagonised.

Schmid concluded that though LMWH might be considered in severe renal insufficiency patients, caution, choice and careful monitoring of these patients are necessary $(\underline{10})$.

The ease of administration of LMWH (single bolus pre-dialysis) and lack of laboratory monitoring are its advantages $(7,16,18,19,20)$.

UFH, besides anticoagulation properties, releases lipoprotein lipase from its active site at the capillary endothelial surface (16).

In our study there was no significant differences in serum total cholesterol, LDL, HDL and TGs after using either anticoagulant, and there was also no significant difference in $\mathrm{Kt} / \mathrm{V}$ values between the groups $(1.5 \pm 1.2$ for Clexane vs $1.4 \pm 0.4$ for heparin; $p=0.6)$.

Al-Saran reported that over 24 weeks tinzaparin sodium resulted in less frequent dialyser and air trap clotting than $\mathrm{UFH}$, and there was no change in serum lipid profile of the patients. The dialysis single pool Kt/V was improved after six months of tinzaparin use $(1.40 \pm 0.28$ for tinzaparin versus $1.23 \pm 0.28$ for heparin)(21).

Saltissi also observed no effects on lipids over three months $(\underline{15})$.

Spaia et al found significantly lower HDL and higher triglyceride concentrations after 33 months of the LMWH treatment (20).

Sabry et al reported no statistically significant differences in serum lipids (cholesterol, LDL, triglyceride and HDL), Hb, white blood cells count and platelet count after changing from UFH to tinzaparin sodium $(\underline{20})$.

\section{CONCLUSION}

Clexane should be considered as effective and safe as UFH and is more convenient than UFH in haemodialysis patients. However, currently direct costs are about $28 \%$ more.

\section{REFERENCES}

1. Gould MK, Dembitzer AD, Doyle RL, Hastie TJ, Garber AM, Low molecular weight heparins compared with unfractionated heparin for treatment of acute deep venous thrombosis: A meta-analysis of randomised, controlled trials, Ann Intern Med, 1999, 130:800-809.
2. Laposata M, Green D, Van Cott EM, Barrowcliffe TW, Goodnight SH, Sosolik RC, The clinical use and laboratory monitoring of low molecular weight heparins, danaparoid, birudin and related compounds, and argatroban: College of American Pathologists Conference XXXI on laboratory monitoring of anticoagulant therapy, Arch Pathol Lab Med, 1998, 122:799-807.

3. Gerlach AT, Pickworth KK, Seth SK, Enoxaparin and bleeding complications: A review in patients with and without renal insufficiency, Pharmacotherapy, 2000, 20:771-775.

4. Hirsh J, Warkentin TE, Shaughnessy SG, Anand SS, Halperin JL, Raschke R, Granger C, Ohman EM, Dalen JE, Heparin and low molecular weight heparin: Mechanisms of action, pharmacokinetics, dosing, monitoring, efficacy, and safety, Chest, 2001, 119:64S-94S.

5. Becker RC, Spencer FA, Gibson M, Rush JE, Sanderink G, Murphy SA, Ball SP, Antmann EM, Influence of patient characteristics and renal function on factor $\mathrm{Xa}$ inhibition pharmacokinetics and pharmacodynamics after enoxaparin administration in non-ST-segment elevation acute coronary syndromes, Am Heart J, 2002, 143:753759.

6. Spinler SA, Inverso SM, Cohen M, Goodman SG, Stringer KA, Antimann EM, Safety and efficacy of unfractionated heparin versus enoxaparin in patients who are obese and patients with severe renal impairment: Analysis from the ESSENCE and TIMI 11B studies, Am Heart J, 2003, 146:33-41.

7. Street A, McPherson J, The new heparins, Aus Prescriber, 1996, 19:104-108.

8. Persson E, Nordenström J, Nilsson Ehle P, Hagenfeldt L, Lipolytic and anticoagulant activities of a low molecular weight fragment of heparin, Eur J of Clin Invest, 1985, 15(4):215-220.

9. Ljunberg B, Jacobson SH, Lins LE, Pejler G, Effective anticoagulation by a low molecular weight heparin (fragmin) in haemodialysis with a highly permeable polysulphone membrane, Clin Nephrol, 1992, 38:97-100.

10. Singer M, McNally T, Screaton G, Mackie I, Machin S, Cohen SL, Heparin clearance during continuous venovenous haemofiltration, Intensive Care Med, 1994, 20:212215.

11. Lim W, Cook DJ, Crowther MA, Safety and efficacy of low molecular weight heparins for haemodialysis in patients with end-stage renal failure: A meta-analysis of randomised trials, J Am Soc Nephrol, 2004, 15(12):3192.

12. Aggarwal A, Whitaker DA, Rimmer JM, et al, Attenuation of platelet reactivity by enoxaparin compared with unfractionated heparin in patients undergoing haemodialysis, Nephrology Dialysis Transplantation, 2004, 19(6):1559. 
13. Lim W, Dentali F, Eikelboom JW, Crowther MA, Meta-analysis: Low molecular weight heparin and bleeding in patients with severe renal insufficiency, Ann Intern Med, 2006, 144(9):673.

14. Guillet B, Simon N, Sampol JJ, et al, Pharmacokinetics of the low molecular weight heparin enoxaparin during $48 \mathrm{~h}$ after bolus administration as an anticoagulant in haemodialysis, Nephrol Dialysis Transplant, 2003, 18(11):2348.

15. Saltissi D, Morgan C, Westhuyzen J, Healy H, Comparison of low molecular weight heparin (enoxaparin sodium) and standard unfractionated heparin for baemodialysis anticoagulation, Nephrol Dialysis Transplant, 1999, 14(11):2698.

16. Schmid P, Fischer AG, Wuillemin WA, Low molecular weight heparin in patients with renal insufficiency, Swiss Med Wkly, 2009, 139(31-32):438-452.

17. Gould MK, Dembitzer AD, Doyle RL, Hastie TJ, Garber AM, Low molecular weight heparins compared with unfractionated beparin for treatment of acute deep venous thrombosis: A meta-analysis of randomised, controlled trials, Ann Intern Med, 1999, 130(10):800-809.

18. Quinlan DJ, McQuillan A, Eikelboom JW, Low molecular weight heparin compared with intravenous unfractionated heparin for treatment of pulmonary embolism, Ann Intern Med, 2004, 140(3):175.

19. Al-Saran KA, Sabry A, Taha M, Ghafour MA, Al Fawzan F, Profile of low molecular weight tinzaparin sodium for anticoagulation during haemodialysis, Saudi J Kidney Dis Transpl, 2010, Jan 21(1):43-9.

20. Spaia S, Pangidis P, Kanetidis D, Longterm effects of low molecular weight heparin in haemodialysed patients, Hellen Nephrol, 1994, 6:426-430.
21. Sabry A, Taha M, Nada M, Al Fawzan F, Alsaran K, Anticoagulation therapy during haemodialysis: A comparative study between two heparin regimens, Blood Coagulation and Fibrinolysis, 2009, 20:57-62.

\section{TABLE 1: DEMOGRAPHIC CHARACTERISTICS OF THE STUDIED PATIENTS}

\begin{tabular}{|c|c|}
\hline Variable & $\begin{array}{l}\text { Studied patients } \\
\qquad \text { (No.44) }\end{array}$ \\
\hline Age (years) & $53.7 .9 \pm 14.2(23-67)$ \\
\hline Sex & \\
\hline Male & $31(70.45 \%)$ \\
\hline Female & $13(29.55 \%)$ \\
\hline BMI (kg/m2) & $23 \pm 3.4(18.2-28.6)$ \\
\hline $\begin{array}{l}\text { Duration on dialysis } \\
\text { (month) }\end{array}$ & $14.6 \pm 3.8(2-54)$ \\
\hline Aetiology of ESRD & $\begin{array}{c}\text { DM (12 patients) } \\
\text { Hypertension (10 } \\
\text { patients) } \\
\text { Glomerulonephritis } \\
\text { (nine patients) } \\
\text { Lupus nephritis (four } \\
\text { patients) } \\
\text { Analgesic nephropathy } \\
\text { (two patients) } \\
\text { APKD (two patients) } \\
\text { Unknown (five patients) }\end{array}$ \\
\hline
\end{tabular}

TABLE 2: LIPID PROFILE AND KT/V, AFTER 16 WEEKS OF UFH AND ENOXAPARIN SODIUM

\begin{tabular}{|c|c|c|c|}
\hline Variable & After unfractionated heparin & After enoxaparin sodium & $P$ value \\
\hline Lipid profile & & & $P=0.53$ \\
Total cholesterol $(\mathrm{mg} / \mathrm{dl})$ & $132.7 \pm 26.54$ & $136.3 \pm 27.8$ & $\mathrm{P}=0.55$ \\
HDL-cholesterol $(\mathrm{mg} / \mathrm{dl})$ & $35.7 \pm 9.8$ & $34.7 \pm 5.2$ & $P=0.6$ \\
TGs & $138.3 \pm 58.6$ & $143.2 \pm 56.8$ & $P=0.6$ \\
\hline KT/V & $1.4 \pm 0.4$ & $1.5 \pm 1.2$ & $P$ \\
\hline
\end{tabular}


FIGURE 1: PERCENTAGE OF CLOTTING IN PATIENTS RECEIVING LMWH AND UFH

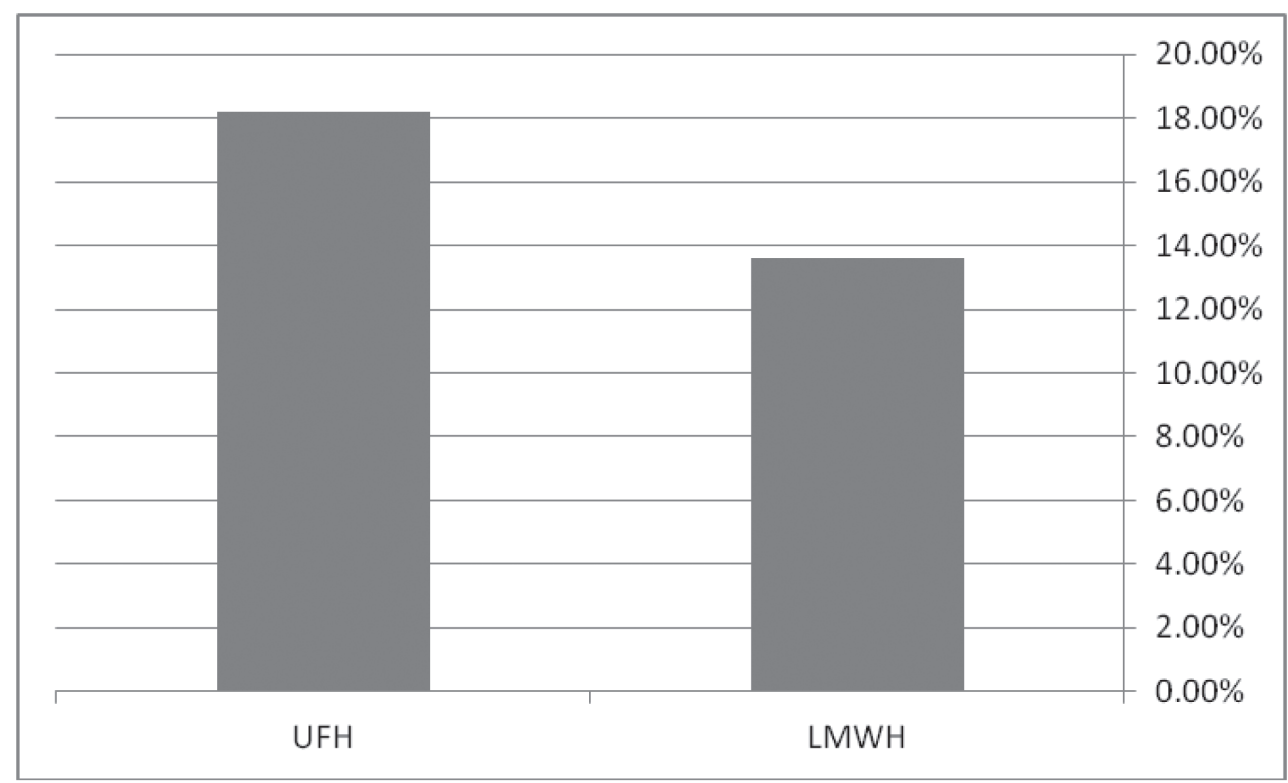

FIGURE 2: PERCENTAGE OF BLEEDING IN PATIENTS RECEIVING LMWH AND UFH

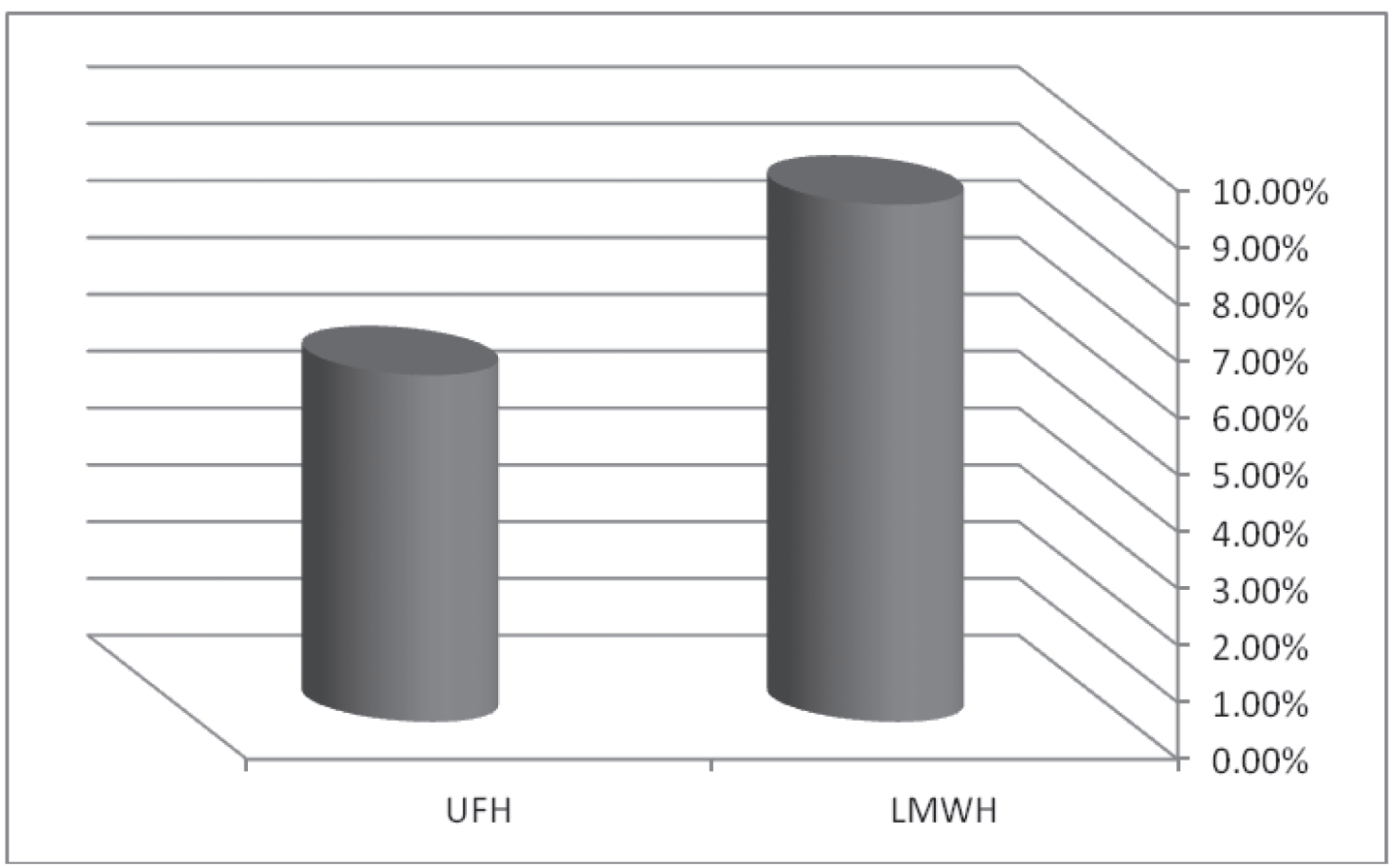

